\title{
Discussion of the Case
}

The patient was shown to the Midland Ophthalmological Society, and to the Section of Ophthalmology of the Royal Society of Medicine. No member could recollect having seen any similar case, and as far as I have been able to ascertain nothing of the kind has been published. No mention was made of anything like it at Professor Vogt's course on the slit-lamp, nor is there any reference to it in his Atlas of slit-lamp microscopy. There is nothing approximating to the condition figured in "The Biomicroscopy of the Living Eye," published in the Transactions of the Société française d'O phtalmologie.*

I am bound to conclude that this case is unique, and that its cause and genesis is unknown. The fact that in certain lights there is a tendency to polychromatism, and that the blue is not seen by transmitted light makes it almost certain that the colour is an interference phenomenon, and is not due to any actual pigmentation.

Because the man is by trade a brass polisher it was suggested both at Birmingham and in London that the colour might be due to the action of copper. This view is quite untenable, for the changes produced by copper in the eye are well known and quite characteristic. The site of the change is not in Descemet's membrane but in the substantia propria deep in the cornea. Here a physical alteration has taken place which has produced a reflecting surface which causes interference of light in such wise that blue predominates. The hue suggests spectral rather than pigment blue.

\section{A RARE FORM OF DEVELOPMENTAL CATARACT}

\author{
BY \\ J. A; Conway and J. Masterton Thomson \\ GLASGOW
}

FOR two reasons the following case seems to us to be worthy of record. Firstly it is of considerable clinical and scientific interest, in that it shows a condition which we deem of rare occurrence, namely a partial cataract, which examination shows to be due to a very infrequently occurring cause. Secondly the case bears a medico-legal interest which is obvious.

The pertinent details of the case are as follows :-In June, 1926, a workman, aged 68 years, was knocking in the lids of some empty

\footnotetext{
*Examen microscopique des affections de la cornée au moyen de la lampe à fente, 1926.

Biomicroscopie de la Chambre Antérieure de l'Iris et du Corps Ciliare, 1928.
} 
barrels when a lid flew up, and a rush of imprisoned air carrying particles of debris, struck him on the right eye. As far as he could tell no foreign body entered the eye, but he received a lot of dirt in the conjunctival sac. On the advice of his doctor he went to hospital, and attended for some weeks on account of some inflammation in the eye. When this passed off he started work again and continued for eighteen months. He maintained that before his accident the right eye had good vision, in fact, that he was a marksman in the army, always shooting with his right eye. After the accident, according to his statement, the sight of the eye gradually deteriorated, and this, and the gradual onset of headaches, caused him to return to hospital, eighteen months after the date of his injury. An X-ray photograph was taken, and he was informed that it was negative to foreign body in the eye or orbital cavity. He was told that he had a cataract in the eye.

Subsequently he claimed that the cataract was a result of the accident he sustained in 1926. Seen by one of us (J.M.T.) for purposes of compensation, a developmental cataract was diagnosed, and it was felt that another examination and opinion was desirable.

The following is the condition.we found. The left eye was a normal eye with a small error of hypermetropia totally manifest. Vision of the left eye unaided was $6 / 18$, and with a plus 2 D.Sph. improved to $6 / 6$.

Externally the right eye was normal in appearance. The iris showed at three o'clock a small area bulged forwards, decolorised and atrophic looking. A brown iris had at this point become grey, and the delicate relief of the iris stroma had become lost. Passing back from this area of iris there was what appeared to be a posterior synechia, ending in a lens opacity behind. Examination with focal illumination and the corneal loupe showed that the socalled posterior synechia in reality came from the collarette of the anterior mesoderm of the iris.

After dilatation of the pupil, examination with the slit-lamp showed an interesting picture. The cornea showed no sign of a previous wound. A narrow band of whitish tissue like a knotted cord was seen traversing the anterior chamber in an antero-posterior direction. The anterior end was attached to the collarette of the iris at three o'clock, whence it dipped over the pupil margin, and pierced the anterior lens capsule, running straight back through clear lens to end in a flattened white opacity.lying in the equatorial plane of the lens. As far as we could judge, this opacity lay at the junction of the foetal and infantile nuclei. The opacity was roughly oval, with the long axis horizontal, and had a slightly irregular though well-defined border. In size it was roughly $3 \mathrm{~mm}$. by $2 \mathrm{~mm}$. Below the lens opacity on the anterior lens capsule, 
were spots of pigment, stellate in shape. The lens was one in which the nuclear zones could not be easily demarcated, and for this reason it can not be stated definitely how far the opacity entered the foetal nucleus. All the previously noted points regarding the iris were better seen under the higher magnification of the corneal

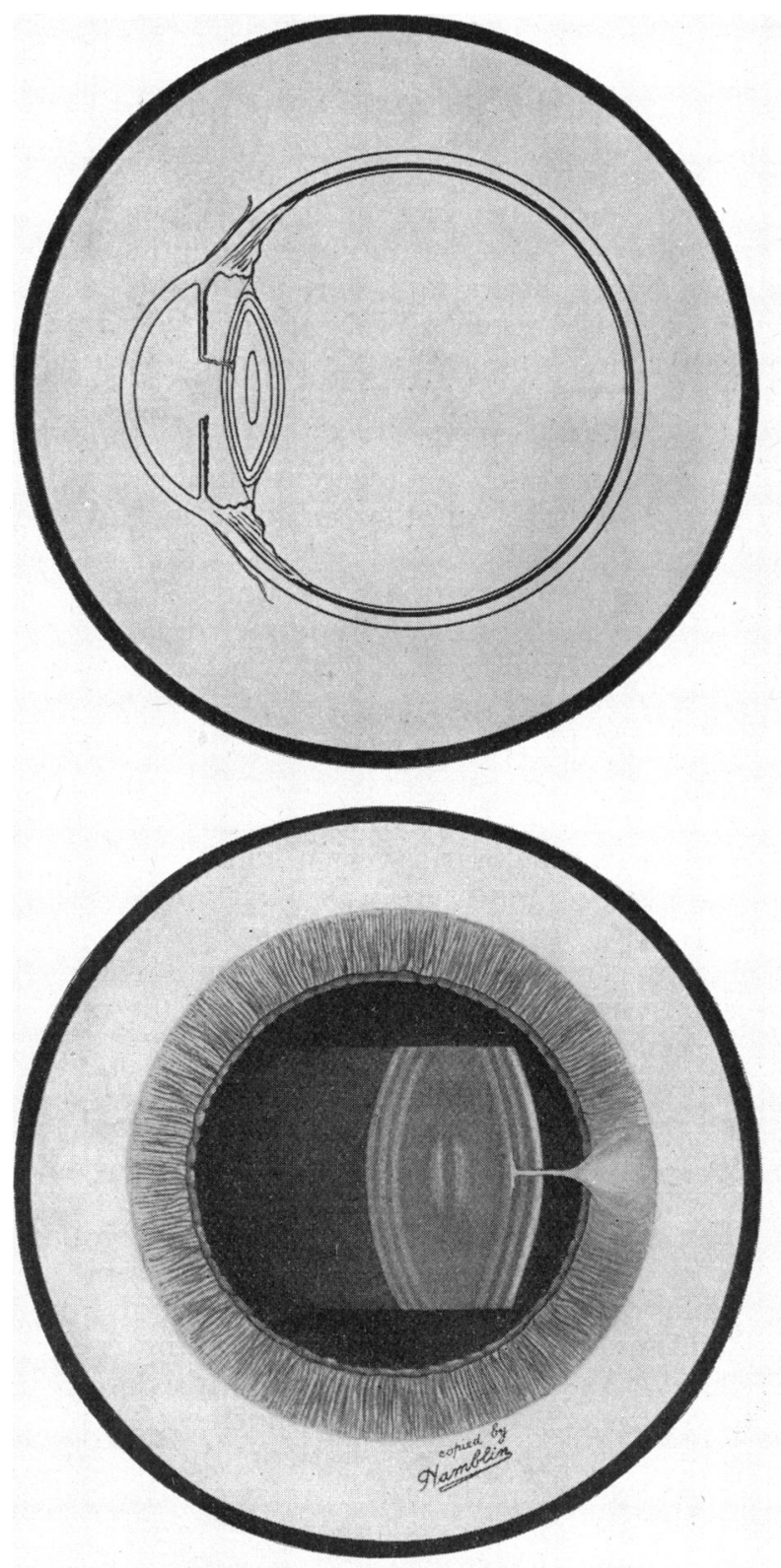


microscope. There was obvious atrophy of the mesoblastic portion of the iris at the affected site. Although retro-illumination did not show transparency, it could be made out that the iris was thinner at this part, and was of a greyish colour stippled with punctate spots of pigment, pointing to a partial atrophy of the retinal pigment layer.

Examination by retinoscopy showed that the eye suffered from a high degree of myopic astigmatism against the rule. The fundus appearance called for no comment other than it was of the myopic type.

The deductions from these observations, and the interpretation of the clinical picture, we take to be as follows. The onset of the partial cataract was of a date far anterior to the accident recounted. The atrophy of the iris had been brought about by the stretching, through the anterior mesoderm becoming attached to the lens. (The tension at this point was so great, that with the dilated pupil there was actual " entropion uveae"). Subsequent growth had increased the distance between the ciliary attachment and the pupil margin, with resulting traction. No doubt lens pressure was also a factor in causing the partial atrophy of the iris.

Regarding the lens opacity; it was an effect, in our opinion, not due to trauma but to natural causes, or more properly speaking, to an aberration in the normal sequence of the steps of the development of the eye. Obviously it was not an anterior polar cataract eccentrically placed, nor could it be accurately described in terms of any of the other well-known types of congenital cataracts. We have consulted some authorities, including slit-lamp literature, but have not come across anything quite similar. We think Miss Mann in her "Development of the Human Eye" gives us the explanation of the condition. Speaking of defects of the lens development, she points out that "delayed separation of the lens vesicle from the surface ectoderm must not be confused with another developmental defect usually called ' delayed separation of the lens from the cornea.' In this latter the lens is perfectly well formed and separated from the surface ectoderm, but owing to delay or defect in the formation of the anterior chamber, the lens remains in contact with the mesoderm between it and the surface too long, so that the growth of the iris is interfered with."

We take it that in this case the delayed and incomplete separation has resulted in leaving one narrow band of the anterior mesoderm attached to the lens capsule, causing the aberration of the lens fibres beneath it, giving the main opacity. In the process of growth new normal lens fibres have been laid down over the opacity, but the band of mesoderm has been too strong to break down, and has been left as a drawn-out cord to its original attachments.

The remarkable points are (1) That there is no capsular opacity 
now, with the exception of the entering cord, and (2) that the lens fibres between the main opacity and the surface of the lens, i.e., adult nucleus and cortex, are normal and transparent, there being not even riders of opacity from the cord in its passage through the lens.

\section{GONOCOCCAL CONJUNCTIVITIS IN A SOCKET}

\section{BY \\ J. H. Doggart \\ LONDON}

IN the literature concerning gonococcal conjunctivitis, I have found no record of this disease affecting a socket. Therefore it may be worth while to report the following case of a woman, aged 40 years, who recently attended St. George's Hospital.

This patient had lost her left eye ten years ago. She had been wearing an artificial eye without discomfort until the day before she first came to hospital, when the socket became painful, and began to discharge pus. On examination, there was diffuse redness, swelling, and tenderness around the left orbital margin. The discharge from the socket was profuse, yellow, and offensive.

Brawny enlargement and tenderness of the left preauricular lymphatic gland was noticed. Her temperature was raised $1^{\circ} \mathrm{F}$. Microscopy of a film of pus revealed gonococci.

Her only eye was protected by a Bullar's shield, and she was admitted to hospital. After two days' treatment with fomentations. frequent irrigation ( 1 in 4,000 solution of potassium permanganate) and argyrol drops, the pain, swelling, and discharge were much relieved, but some anxiety was felt for the eye, which, under the Bullar's shield, showed conjunctival injection and a slight mucopurulent secretion. This secretion, however, contained no organisms but staphylococci. Six days after admission to hospital, the socket ceased to discharge.

A swab was taken both before and after irrigation, but no more gonococci were found. There was no further trouble either in the eye or in the socket. Gynaecological examination showed that this patient was suffering from acute gonorrhoea. Gonococci were detected in a urethral smear of pus.

In this patient the right eye was microphthalmic and showed coarse lateral nystagmus; there was an extensive coloboma of the choroid in the usual position, involving the disc. Vision was reduced to $6 / 24$.

I wish to thank Mr. R. R. James for kindly allowing me to publish this case. The bacteriological investigations were the work of Dr. E. L. Hunt, bacteriologist to St. George's Hospital. 